\title{
A Naturalistic Understanding of Justice Under Pandemic
}

\author{
Jingtao Jiang \\ Research Centre of Medical Humanities, Zunyi Medical University, Zunyi, China
}

Email address:

jjt@zmu.edu.cn

\section{To cite this article:}

Jingtao Jiang. A Naturalistic Understanding of Justice Under Pandemic. Journal of Political Science and International Relations. Vol. 3, No. 3, 2020, pp. 84-91. doi: 10.11648/j.jpsir.20200303.15

Received: August 31, 2020; Accepted: September 21, 2020; Published: September 30, 2020

\begin{abstract}
The coronavirus pandemic has sparked controversies over freedom, equality and democracy, some of which affirm the government's epidemic control measures and some deny them. Through the further analysis of the meaning of freedom, equality and democracy, we demonstrate that the epidemic prevention and control measures are in line with positive freedom, proportional equality and republican democracy, but are contrary to negative freedom, absolute equality and liberal democracy. Further evaluation involves the criterion of justice. The traditional normative justice standard is the axiom system constructed by the rational man, but the problem is that the rational man here is not a real man. This paper advocates a kind of naturalistic standard of justice based on the needs and satisfactions of human being's survival, development and balance. According to this view of justice, freedom is the ability and degree of a living system to meet its internal needs. The pursuit of freedom is the instinctive response of a living system to the law of survival and development, and therefore is just. Equality reflects the comparison of the influence of one living system with another living system. Absolute equality with equal influence does not exist, and the enforcement of such equality only hinders the strong and indulges the weak, which is not in line with the law of survival and development of the life system and is therefore unjust. Only the proportional distribution according to the actual influence of living systems is fair, conducive to the survival and development of living systems, and therefore just. Democracy reflects the comparison of influence between the middle class that composed of lots of ordinary people, and the upper class that composed of a few elites, in one same group of living systems. The middle class overpowers the upper class and the upper class overpowers the middle class, which are both bad for the survival and development of living systems and therefore unjust. Only when the middle class and the upper class have equal influence or simply eliminate the classes can they unite and represent the public will of all members. Such a republican system is conducive to the survival and development of the living systems and thus is just.
\end{abstract}

Keywords: Coronavirus Pandemic, Normative Justice, Naturalistic Justice

\section{Introduction}

A novel coronavirus pandemic broke out in China in January, in Europe in February, in the United States in March, and is still not fully under control now. All countries are facing with the same virus, and all the scientists have had a consensus on the prevention and control measures, but the actual implementations in different countries are very different and mainly because of their different ideologies, values and historical traditions. However, the corresponding reflective discussions about these measures are gradually focusing on some core concepts of freedom, equality and democracy.

In China, where Marxist ideology has long been dominant, there have been some appeals for freedom during the urgent period of the epidemic, among which "the appeal of ten professors in wuhan" is very representative. In their letter of appeal, they argued that whistleblower li wenliang "did not harm the state, society, collective interests and other civil liberties and rights... He took responsibility for the safety of the public", and those who restricted li before must "admit that the foregoing was totally wrong and take this as an example to put an end to the practice of restricting freedom of speech." [1]

In Italy, Agamben's article sparked a debate. He argues that the state of collective panic over infectious disease justifies the government's encroachment on individual freedom, and further makes centralization of power in this exceptional state a regular political practice. [2] In France, Latour rethinks the 
state's administrative model that relies on statistical reasoning and biological power. [3] In the United Kingdom, Zizek argues that the government should act aggressively and enforce segregation, which would better bring unity and reduce inequality. [4]

In America, there are also many different voices. Sandel argues that in an epidemic we need to seek the common good, to reject utilitarianism and Darwinism, to treat the poor and the rich equally, and to provide universal health care. [5]Fukuyama believes that the expansion of executive power under emergency state is a political practice that has been promoted continuously since the founding of the United States, but the Trump administration's consistent reckless actions may pose a serious crisis of confidence in this tradition. He also argues that what matters most is not the type of regime, but whether citizens trust their leaders and whether those leaders lead a competent and effective government.[6]Harvey believes that the liberation Marx pursued requires collective action, and so we need to take collective action to control the spread of infectious diseases in the current epidemic. Such collective action is necessary for us to become free individuals and live in the way we like. [7]Butler believes that social and economic inequality make the virus discriminatory, and then she desires for radical equality. [8]

All this shows that scientists have reached a consensus on the prevention and control measures, but countries with different political, economic and cultural backgrounds perform differently in the implementation. These different performance have inspired similar reflections focused on freedom, equality and democracy. It is quite a good opportunity to test the theoretical concepts of freedom, equality and democracy with experience and practice, so as to deepen our understanding of these concepts.

In view of this, this paper attempts to analyze the practices and theories of freedom, equality and democracy under this coronavirus pandemic. First of all, it reviews the reflections of some famous scholars on the prevention and control measures of this pandemic. Secondly, it deeply analyzes the meaning of freedom, equality and democracy, and then to use them to evaluate the epidemic prevention and control measures. Thirdly, the further in-depth evaluation involves the standards of justice, so this paper compares the normative view of justice with the naturalistic view of justice. Finally, this paper proposes and elucidates a naturalistic view of justice based on the needs and satisfactions of living system of man to survive, develop and balance.

\section{Freedom, Equality and Democracy Under Coronavirus Pandemic}

From the previous discussion, we can see that the relevant disputes caused by the prevention and control measures of coronavirus pandemic mainly revolve around the topics of freedom, equality and democracy. Some scholars think that the government's measures are too severe, others think that the government's measures are too weak, and whether they are too severe or too weak will hinder the realization of freedom, equality and democracy. This requires us to further rethink what is freedom, equality and democracy, and whether the government's measures are in line with it.

\subsection{Freedom}

With regard to the concept of freedom, Berlin's distinction between negative and positive freedom is inescapable. Berlin thinks that the positive freedom is "the freedom which consists in being one's own master", the negative freedom is "the freedom which consists in not being prevented from choosing as I do by other men".[9] In fact, the negative freedom here is a kind of freedom that can be acquired without the efforts to break restrictions or obstacles, so can be acquired or realized easily. Positive freedom, on the other hand, can only be acquired or realized after efforts are made to overcome obstacles. Therefor, we can actually understand Berlin's two concepts of freedom according to whether or not it is necessary to overcome obstacles, and then to use it to further analyze the concept of freedom. The traditional discussion of freedom is mainly about two aspects: a person's self-will towards external objects outside him, and a person's self-will towards internal objects inside him. As for the freedom of the self-will itself, we will not discuss it here. In both cases above there are negative freedom that does not require effort to overcome obstacles, and positive freedom that requires effort to overcome obstacles. This way of understanding and interpretation can integrate the confusing and complex concept of freedom. The negative freedom of a person's self-will towards his external objects refers to the freedom that requires little or no effort to overcome obstacles, such as breathing the air and looking at objects, while the positive freedom refers to the freedom that requires great efforts to overcome obstacles, such as woman's voting rights and homosexual marriage. The negative freedom of a person's self-will towards his internal objects also refers to the freedom that requires little or no effort to overcome obstacles, such as masturbation and self-harm, while the positive freedom refers to the freedom that requires great effort to overcome obstacles, such as abstinence and composure.

In this coronavirus outbreak, those who prefer not to wear masks and not be socially isolated first have to overcome the government's control measures, which could have been achieved with little or no effort in normal days. That is to say, the original negative freedom in normal days has become the positive freedom in current epidemic. The key to this transformation is the obstacle of the government's epidemic prevention and control measures, which is an obstacle to the original negative freedom. Those who prefer their own and others' life safety first must work hard to overcome the obstacle of infection and transmission of novel coronavirus, which is a typical positive freedom, and their "effort" is to follow the government's epidemic prevention and control measures. In conclusion, the government's epidemic prevention and control measures hinder people's negative 
freedom, but they are just the necessary "effort" step to realize people's positive freedom.

\subsection{Equality}

With regard to the concept of equality, it has been inseparable from the concept of justice since Rawls. Rawls's first principle of justice is "each person is to have an equal right to the most extensive basic liberty compatible with a similar liberty for others".[10] That is to pursue the absolute equality of all people under an abstract standard. For other concrete standards such as income and wealth equality is the second principle that "social and economic inequalities are to be arranged so that they are both (a) reasonably expected to be to everyone' advantage, and (b) attached to positions and offices open to all". [10] So on the whole, Rawls's two principles of justice tend to pursue an absolute and complete equality. In addition to this kind of equality, Dworkin also emphasizes another kind of relative and proportional equality. According to Dworkin, some of the differences between people are due to natural luck or things that can be obtained without effort, such as beauty, birth, etc., while others are due to luck of choice or hard work, such as wealth, fame, etc. The former is unjust and needs to be rectified by taxing the strong to compensate for the weak, while the latter is just. Rawls only focuses on equality in the first sense and ignores equality in the second sense.[11]This is similar to Aristotle's numerical equality and proportional equality. "now equality is of two kinds, numerical and proportional; by the first I mean sameness or equality in number or size; by the second, equality of ratios". [12]

In this coronavirus outbreak, even in the collectivistic and socialistic China, where the slogan of "receive and cure as much as you can" is proposed, there is an inequality between those with money and power who could get better treatment and those without money and power who could only wait in line, not to mention in individualistic and capitalistic America. So both of them violate or fail to achieve the first kind of absolute and complete equality. However, in the case of scarce medical resources, the selective admission of different patients according to their life values has been a widely accepted medical ethical standard, and this is obviously a relative and proportional equality. In conclusion, even if the government's epidemic prevention and control measures do not achieve the absolute equality of the first kind, they are also largely in line with the relative equality of the second kind.

\subsection{Democracy}

With regard to the concept of democracy, liberal democracy and republican democracy have been the major schools of interpretation in history, while the so-called communitarian democracy can be basically attributed to republican democracy. Who holds the power becomes the key to distinguish them. The heart of liberal democracy is by the majority of citizens that the power is controlled. "The majority having, as has been showed, upon men's first uniting into society, the whole power of the community naturally in them, may employ all that power in making laws for the community from time to time, and executing those laws by officers of their own appointing, and then the form of the government is a perfect democracy". [13] The majority here is the dominant one among the many interest communities formed through competition and cooperation on the basis of each individual' interest. At the same time, it respects the independent existence of other individuals and minority groups and makes some appropriate compromises according to the size of their influence. "For that which acts any community, being only the consent of the individuals of it, and it being one body, must move one way, it is necessary the body should move that way whither the greater force carries it, which is the consent of the majority". [13] The heart of republican democracy is by the all of citizens that the power is controlled. "Each of us puts his person and all his power in common under the supreme direction of the general will, and, in our corporate capacity, we receive each member as an indivisible part of the whole". [14] The all of the citizens here are the collective will formed through consultation and dialogue on the basis of each individual reason. At the same time, it tries to persuade a small number of dissenting individuals or groups within it and exert appropriate coercive control. "Find a form of association that will bring the whole common force to bear on defending and protecting each associate's person and goods, doing this in such a way that each of them, while uniting himself with all, still obeys only himself and remains as free as before." [14]

In this coronavirus outbreak, the government's epidemic prevention and control measures are, in the liberal democratic view, temporary and special rights granted by a community of interests composed of the majority of citizens, which will be quickly withdrawn after the state of emergency ends. Besides, although these measures are in line with the interests of the majority of citizens, they are not under the direct control of them. Thus the government is out of the control of the public and does not need to consider the opinions of the majority of its citizens, let alone those of other individuals and minority groups. This is definitely a violation of liberal democracy. In the republican democratic perspective, the government's epidemic prevention and control measures are part of the long-term and normal rights granted by the rational community composed of all citizens, and will voluntarily shrink after the emergency is over. Besides, these epidemic prevention and control measures reflect the public will of all citizens. At the same time, the rational community of all citizens also tries to persuade a small number of individuals and minority groups that do not cooperate or even endanger the public will, and impose appropriate coercive restrictions. This is definitely consistent with republican democracy. In conclusion, the government's epidemic prevention and control measures are against liberal democracy and in line with republican democracy. 


\section{Normative Justice and Naturalistic Justice}

In the previous discussion, we divide freedom into negative freedom and positive freedom, divide equality into absolute equality and relative equality, and divide democracy into liberal democracy and republican democracy. On the basis of this distinction, it is further demonstrated that the covid-19 prevention and control measures violate negative freedom, absolute equality and liberal democracy, but conform to positive freedom, relative equality and republican democracy. This makes it difficult for us to make a final evaluation of the epidemic prevention and control measures, which further raises the question of standard of justice.

Rawls's idea of justice is very representative, he thinks that"Justice is the first virtue of social institutions, as truth is of systems of thought. A theory however elegant and economical must be rejected or revised if it is untrue; likewise laws and institutions no matter how efficient and well-arranged must be reformed or abolished if they are unjust". [10] It's like a set of criteria $X$, which we use to evaluate the moral facts and moral norms of society, and what conforms to it is just and what does not conform to it is unjust. But the question is where does the sanctity or the supremacy of this set of criteria come from? Rawls argues that it comes from the construction of the rational man, and so the principles of justice are those which are accepted by rational men who seek to advance their own interests. The rational man here eliminates the interference of internal subjective preference and external objective context, thus being able to give the same set of constructions of abstract logic in all cases. "The idea of the original position is to set up a fair procedure so that any principles agreed to will be just." [10] In essence, the justice system constructed by rational man in Rawls is similar to a axiom system constructed by robot, which is derived according to the rules of logical calculus on the basis of initial conditions composed of original definitions and original propositions. But the question is whether this is human justice or robot justice? Even if we put aside the robot to talk only about the rational man, it is also not a human being, because it lacks the essential elements of human existence such as attitude, emotion, desire, etc., so isn't this a set of inhuman justice? This kind of justice is a set of rules and orders derived from the calculation after setting the original concepts and axioms. These original concepts and axioms are rooted in rationality but are essentially a kind of intuition, convention or subjective construction, and are a kind of normative non-human justice, rather than a naturalistic view of real living human justice. Therefore, justice must be built on the basis of living human beings, and any justice based on the abstract human beings is not the justice we really need.

The living man in the perspective of naturalism can be regarded as a dynamic living system. This point can be sorted out and further constructed from the clues of process philosophy, system philosophy and ecological ethics. Whitehead's process philosophy, a precursor to today's systems philosophy, holds that the real world is a process and this process forms the actual existence. Actual entities interact with each other through "prehensions", both positive and negative. "an actual event is an achievement for its own sake, a grasping of diverse entities into a value by reason of their real togetherness in that pattern, to the exclusion of other entities." [15] Organisms evolve by "prehensions", thereby forming a purpose-driven value realization process. "The problem of evolution is the development of enduring harmonies, of enduring shapes of value, which merge into higher attainments of things beyond themselves."[15] The study of value in systems philosophy is only a small part of its larger framework, and it is not often that much effort is devoted to it, but most systems philosophers would agree that: adaptive self-stable states are the goals of complex systems, and objects that can meet these goals have values. Typically, laszlo argues, "My preference, however, is to define values in positive terms as states of the system specified by its incorporated program and realized through normative interaction with the milieu". [16] A person's inner goal is determined by his genes and is called normative value, and the satisfaction of this goal by an external object is called manifest value, "Manifest values are expressions of the states of adaptation reached by the system in the course of its interactions with its relevant environment. Normative values underlie the manifest values as the values programmed into a thermostat underlie the thermometer readings registering the real world temperature of the air". [16] Besides, "In a systems oriented value theory, where the interaction of object and subject is the decisive element in the determination of value, the specious dichotomy of facts and values disappears". [16] Ecological ethicists have pushed the study of value further, believing that the survival and reproduction of an organism are its intrinsic values, and the means to achieve these ends are its extrinsic values. "its internal functioning as well as its external activities are all goal-oriented, having the constant tendency to maintain the organism's existence through time and to enable it successfully to perform those biological operations whereby it reproduces its kind and continually adapts to changing environmental events and conditions". [17] The value of organism is only a part of the overall value of ecosystem and must be subordinated to the higher ecosystem value, "A thing is right when it tends to preserve the integrity, stability, and beauty of the biotic community. It is wrong when it tends otherwise". [18] In the light of the brief academic history here, we can see that the Whitehead's process philosophy has consciously understood and interpreted the value phenomenon of living body from a systematic perspective. The systems philosopher Laszlo had a clear discussion of the value phenomenon of man as a living system, but unfortunately it did not expand further. When it comes to ecological ethicists, although they also study the value phenomenon of human being as a living system, they focus on the large ecological system in natural world, in which human being is just a small link. Here we are going to further take the human living system as the center and study the 
value demand and value satisfaction of its survival and development. In fact, it is a matter of good and bad, right and wrong for the human living system, and also a matter of justice standard for it. This justice standard takes the survival and development of human living system as the source of sanctity and supremacy, and then to construct a set of evaluation standards of human behavior.

\section{Freedom, Equality and Democracy in the View of Naturalistic Justice}

For the living system of man, as for any other natural physical system, there is an inherent instinct to maintain survival and achieve development. Survival here is the pursuit of a state of balance, trying to meet the internal needs and eliminate external interference, so as to achieve a state of carefree satisfaction. However, the inner needs of the living system are divided into high and low levels, and there are high-level needs waiting to be satisfied after low-level needs are satisfied. At the same time, external interferences are divided into short and long terms, and there are long-term interferences waiting to be eliminated after short-term interferences are eliminated. Therefor, the human living system must continue to develop in order to achieve its high-level and long-term survival. Therefor, the development here is actually a special kind of survival, a higher level and longer term survival, so as to achieve the eternal existence of the state of satisfaction.

Balance is the eternal pursuit of the survival and development of a system, and the concrete way to achieve it is to adjust the internal structure or to adjust the external relations. The adjustment of the internal structure is actually to adjust the internal subsystems, so that the resultant force of them can reach zero, and then to reach balance. The adjustment of the external relations is because that the interaction forces between the internal subsystems still cannot be zero after adjustment, so the reluctant force will drive the system to interact with its external relations, until the external interaction forces reach zero, and then to reach balance. For the living system of man, if its inside and outside are both balanced, then there is no demand and no interference. For such a balanced system only the state of equilibrium itself is valuable, other things are of no value and things that might potentially upset the balance are of negative value. If a living system' inside and outside are both out of balance, one way to achieve balance is to adjust its internal subsystems so that the interaction forces are balanced at zero, and the other way is to adjust its relationship with the external peer systems so that the interaction forces are balanced at zero. In the former, one of the two sides in the unbalanced state constitutes a demand of value, while the other constitutes a satisfaction of value. Such as the demand of sex and the satisfaction of masturbation. In the latter, the system as a whole creates a need, while the external peer systems serve as a satisfaction, such as hunger and chicken. Therefor, A state of balance can be reached when the needs of human survival and development are met. This is the sanctify and supreme justice for mankind. Based on this sanctity and supremacy, we then to further construct the evaluation system of human behavior concerning freedom, equality and democracy.

\subsection{Freedom}

As for freedom, a living system with internal and external balance has no demand of value and satisfaction of value, so there is no so-called freedom or non-freedom for it. Freedom must be derived from living systems with value needs. When the value needs are possible to be met, then it has the potential for freedom, and when the value needs are real to be met, then it has the real freedom of reality. In the process of fulfilling this need for freedom, firstly, there is no freedom without effort at all, because the balance between the force of "demand" and the force of "satisfaction" requires work, even if the work is very small, but there is work. For example, the freedom to breathe air needs to overcome the gravity of the air. Secondly, some demands can be directly and simply balanced with little effort. According to our previous review of different views of freedom in history, this can be regarded as negative freedom. While some demands can be indirectly, complexly balanced with a great deal of effort, and this can be regarded as positive freedom. Finally, because negative freedom and positive freedom are merely differences in the degree of effort, not in essence, and they both need to work to overcome obstacles, we can actually eliminate negative freedom and only have positive freedom left. In this way, we simplify the understanding of freedom. There are potential freedom and real freedom, and the latter is essentially a positive freedom.

These are only the facts of the existence of the freedom-related phenomena of the living system of man, rather than the knowledge of whether they are conducive to human survival, development and balance, which is the source of the sanctity and supremacy of the standard of justice. So further, for the survival, development, and balance of this living system, real freedom takes precedence over possible freedom, and the less effort it takes the better. Applying this view of freedom to the evaluation of the epidemic prevention and control measures, these measures are less costly than saving lives after infection, so they are consistent with freedom, and are consistent with justice.

\subsection{Equality}

As for equality, it concerns the relationship between living systems. Suppose the driving force of the demand of living system $\mathrm{A}$ is $\mathrm{Fa}$, the driving force of living system $\mathrm{B}$ is $\mathrm{Fb}$, and the driving force of the higher-level system $\mathrm{C}$ composed by systems $\mathrm{A}$ and $\mathrm{B}$ is $\mathrm{Fc}$. If $\mathrm{Fa}$ and $\mathrm{Fb}$ have equal proportions in $\mathrm{Fc}$, then $\mathrm{A}$ and $\mathrm{B}$ are equal in C. Just as Marry contributed 50\% and Max contributed 50\% to make up 100\% of the shares of the company, and then Marry and Max are equal in the company. If $\mathrm{Fa}$ and $\mathrm{Fb}$ have different proportions in $\mathrm{Fc}$, and $\mathrm{Fa}$ is ( $\mathrm{fa}-\mathrm{fb}$ ) higher than $\mathrm{Fb}$, then the influence of $\mathrm{A}$ 
is (fa- $\mathrm{fb}$ ) higher than that of B in C. Just as Marry contributed $55 \%$ and Max contributed $45 \%$ to constitute $100 \%$ of the shares of the company, the influence of Marry is $10 \%$ higher than that of Max in the company. In real life, the driving force of value demand is usually the influence or power that a person can mobilize. Its calculation is quite complex and depends on a person's endowment, personality, experience, resources, luck, etc. We could call it "real influence". Therefor in real life, there is no such thing as an "equal" distribution based on equal proportion, what exists can only be "fair" distributions based on different proportions. There is no "equality" but only "fairness" in the naturalistic world.

These are only the facts of the existence of the fairness-related phenomena of the living system of man, rather than the knowledge of whether they are conducive to human survival, development and balance, which is the source of the sanctity and supremacy of the standard of justice. So further, firstly, there can be no precise calculation of the real influence of a living system, but only an approximate numerical interval. The real influence of the different living systems in the approximate numerical interval can be regarded as equal, so it can be said that they are all in the same level. Secondly, the living systems in the same level should be distributed "equally" due to their same real influences, while the living systems in different levels should be distributed "fairly" due to their different real influences. Finally, the real influence of living systems in any level cannot be completely zero, as long as it is not zero, it needs to be fairly distributed according to its proportion. This proportional distribution allows the welfare of its members to increase with the progress of the group. In general, if the real influence gap between living systems is large and therefore at different levels, we need to distribute according to the principle of fairness. If the real influence gap between living systems is small and therefore at the same level, we need to distribute according to the principle of equality. When a living system's real influence increases, its level goes up, and when it decreases, its level goes down. The real influence of a living system will never decline to completely zero and then be obsoleted, there should always be a guarantee of equal welfare waiting for her. Applying this view of equality, or rather fairness, to the evaluation of the epidemic prevention and control measures, these measures are basically equal within the same level and fair between different levels, and are consistent with justice.

\subsection{Democracy}

As for democracy, it concerns the relationship between different levels composed of living systems. From the macroscopic scale, within a group composed of living systems, because of the random probability distribution of factors such as endowment, personality, experience, resources, and luck, the majority of ordinary members are neither too high nor too low in influence, but at a similar level. We may call it the "common level", and the overall influence in the group is quite large. A small number of weak members are at a similar lower level due to the abnormal probability, and the influence in the group is small and can be ignored temporarily. At the same time a small number of strong members are at a similar higher level due to the abnormal probability, and the influence in the group is quite large. We may call it the "higher lever". Therefore, in this group of living systems, it mainly involves the proportion of influence between the "common level" and the "higher lever", and this is a dynamic process. In cases of little division of labor, exceptionally strong members can exert strong influence alone without the help of ordinary members, so the influence of the higher level is more than that of the ordinary level. This can be called a aristocratic regime. In cases of a large number of division of labor, exceptionally strong members need the assistant of ordinary members to jointly dominate powerful influence, which inadvertently enhances the influence of ordinary members and eventually make it exceeds that of senior members through the accumulation of numbers. This can be called a democratic regime. In case of infinite division of labor, exceptionally strong members and ordinary members must work together to wield powerful influence, which leads the influence gap between them narrow to nearly zero and we can say that they are all in the same level. This can be called a republican regime. Therefore, according to the proportion of the influence of ordinary members and senior members within the group, there are three situations: the aristocratic regime, the democratic regime and the republican regime.

But this is within the group of living systems, and if we zoom in and think about the group itself, there will be some interesting findings. From the outside, the gap between all the members within the group is very small, and the gap with other things outside is very big. Thus all the internal members of the group are approximately in the same "group level", facing things outside with a macroscopic false general will that ignores the differences of the internal members. This is a false republican regime that ignores the differences between its internal different levels. If this false republican system seen from the outside is actually an aristocratic system inside, then it can be called a false republican system of aristocracy. If it is actually an democratic system inside, then it can be called a false republican system of democracy. If it is actually an republican system inside, then it can be called a true republican system. And because all members of the group are in a similar "group level" seen from the outside, so the influence gap between its top and bottom members is very limited from the outside. Although the influence of lower level members increases very little, their internal level will rises with the growth. But the internal level of higher members will not change with the growth of their influence because of the limit of the "group level". Unless they jump out of their "group level" and move up to a different, higher "group level", or just move up their own "group level" to a higher level. The former corresponds to the individual jump of senior members, while the latter corresponds to the overall jump of their group. It is far more difficult to jump by virtue of the personal influence of senior members than by virtue of the influence of their group. Senior members will enter the 
lowest level of the new "group level" after their jump by virtue of their personal influence, while they will still be at the top of the new "group level" if the group as a whole jumps. So group jump is better than individual jump. The group jump first needs to elevate the internal ordinary members to the level of senior members, so as to form a "group level" of real republican system, and then the group influence can be concentrated to seek a breakthrough to a higher "group level". If senior members are dragged down to the level of ordinary members, this will solidify the "group level" and will never come to a breakthrough. Besides, when a "group level" jumps to a higher "group level", it will be the small number of elites that adapt quickly and rapidly to expand their influence far beyond the general public. This would create a real aristocratic system. Then, as the influence of the general public grows and exceeds that of a few elites, this aristocratic system will evolve into a real democratic system. Finally, the limit of "group level" leads to the fusion of elites and ordinary people, which will form a real republican system. When the "group level" of this republican system once again jumped to a new "group level", these above three systems will begin a new cycle. Therefore, there is no eternal hierarchical order in the social system. Unless the development of human society has reached its ultimate form and there is no new "group level" to jump to, this cycle constitutes a real and eternal process of progress.

These are only the facts of the existence of the democracy-related phenomena of the living system of man, rather than the knowledge of whether they are conducive to human survival, development and balance, which is the source of the sanctity and supremacy of the standard of justice. So further, the false republican system of the aristocracy suppresses the ordinary members, the false republican system of the democracy suppresses the senior members, and only a true republican system is beneficial to all. A true republican system, which elevates the internal levels of lower members and the external levels of the higher members, is also true justice. The false republican system is justice if it is used to promote the construction of a real republican system, and it is false justice if it is used to defend the real aristocratic system or the real democratic system. Applying this view of democracy, or rather republic, to the evaluation of the epidemic prevention and control measures, these measures, whether in the aristocratic system or in the democratic system, are in fact the manifestation of a false republican system. They are false justice if they are used to defend the old system, and true justice if they are used to promote the new system.

\section{Conclusion}

To sum up, this paper starts from the analysis of freedom, equality and democracy under the epidemic situation, and leads to the criticism of the concept of justice from the perspective of traditional normalism. Then it argues that the concept of justice should be interpreted from the perspective of naturalism and further analyzes the concepts of freedom, equality and democracy from this naturalistic perspective.

One might argue against the naturalistic axiology based on living systems, that robots are not human beings, rational human beings are not human beings, and that systematic human beings are not complete real human beings either. Because real human beings have spiritual content, which cannot be explained by the existing system theory.

Firstly, the development of cognitive science in modern times has enabled us to have a deeper understanding of the human mind. However, there are still some mind-specific phenomena such as qualia, intentionality and emergence, which make it impossible for us to fully explain them with physical and natural objects. However, given the fact that science and technology have slowly accumulated and progressed in human history, we believe that this is only a question of historical limitations that will be gradually revealed with the development of science and technology. Secondly, compared with the traditional normative rational man explanation, the naturalistic systematic man explanation is the inference of the best explanation. Because the addition of an invisible and intangible AD hoc hypothesis of spiritual mind, does nothing to advance our understanding and grasp of the relevant phenomena, the performance of the systemic human hypothesis is undoubtedly much better. Thirdly, the traditional normative view of justice emphasizes a kind of "ought" based on the axiom system constructed by rational man, while here the naturalistic view of justice emphasizes a kind of true or false based on the demand of the existence, development and balance of the living system and its satisfaction. The justice of the former is guaranteed by the system of axioms, but it only grasps a few original definitions and a few original axioms, and it is easy to become paranoid and extreme. The Justice of the latter is guaranteed by the natural world itself and will not stray too far. Finally, we do not reject the traditional normativism completely here, but are more dominated by naturalism and supplemented by normativism. Because of the historical limitations of understanding the nature of human and society, our naturalistic view of justice cannot reach the same degree of truth as the law of nature, so we must tolerate the existence of some subjective normative conventions.

\section{Acknowledgements}

This thesis is supported by the Social Science Foundation of Guizhou Province, NO: 19GZYB61.

\section{References}

[1] Tianyu Feng et al., 2020, The appeal of ten professors in wuhan. [On-line]. Available: http://mp.163.com/v2/article/detail/F4RCUGA705199UR3.ht $\mathrm{ml}$ (accessed May 10, 2020).

[2] Agamben, G. 2020. Lo stato d'eccezione provocato da un'emergenza immotivata. [On-line]. Available: https://ilmanifesto.it/lo-stato-deccezione-provocato-da-unemer genza-immotivata/ (accessed May 10, 2020). 
[3] Latour, B. 2020. Is this a dress rehearsal? [On-line]. Available: https://critinq.wordpress.com/2020/03/26/is-this-a-dress-rehea $\mathrm{rsal} /($ accessed May 10, 2020).

[4] Zizek, S. 2020. Is barbarism with a human face our fate? [On-line].

Available: https://critinq.wordpress.com/2020/03/18/is-barbarism-with-ahuman-face-our-fate/(accessed May 10, 2020).

[5] Friedman, T. L. 2020. Finding the 'common Good' in a pandemic. [On-line]. Available: https://www.nytimes.com/2020/03/24/opinion/covid-ethics-po litics.html?searchResultPosition=6 (accessed May 10, 2020).

[6] Fukuyama, F. 2020. The thing that determines a country's resistance to the coronavirus [On-line]. Available: https:/amp.flipboard.com/@TheAtlantic/the-thing-that-deter mines-a-country-s-resistance-to-the-coronavirus/a-ToWNMRv NRAK1vsmyhx_6Fw\%3Aa\%3A3199527-c98427eb57\%2Fth eatlantic.com (accessed May 10, 2020).

[7] Harvey, D. 2020. We need a collective response to the collective dilemma of coronavirus. [On-line]. Available: https://www.jacobinmag.com/2020/04/david-harvey-coronavir us-pandemic-capital-economy (accessed May 10, 2020).

[8] Butler, J. 2020. Capitalism has its limits. [On-line]. Available: https://www.versobooks.com/blogs/4603-capitalism-has-its-li mits (accessed May 10, 2020).

[9] Berlin, I. Liberty: Incorporating Four Essays on Liberty. Oxford: Oxford University Press, 2002, P178.
[10] Rawls, J. A Theory of Justice. Cambridge: The Belknap Press of Harvard University Press, 1971, p60, p3, p118.

[11] Dworkin, R. (1981). What is equality? Part 2: equality of resources. Philosophy and Public Affairs, 10 (4): 283-345.

[12] Aristotle, and Benjamin Jowett. 1999. Politics. Kitchener, Ont: Batoche Books, 1999, p109.

[13] Locke, J. 1690. Two Treatises of Government. [On-line]. Available: https://www.yorku.ca/comninel/courses/3025pdf/Locke.pdf (accessed May 10, 2020). p161, p146.

[14] Rousseau, J. 1762. The Social Contract. [On-line]. Available: https://www.earlymoderntexts.com/assets/pdfs/rousseau1762. pdf (accessed May 10, 2020). p7, p6.

[15] Whitehead, A. N. Science and the Modern World. New York: The New American Library, 1948, p106, p96.

[16] Laszlo, E. (1973). A systems philosophy of human values. Behavioral Science, 18 (4): 250-259.

[17] Taylor, P. Respect for Nature, Princeton: Princeton University Press, 1986, pp121-122.

[18] Lepold, A. A Sand Country Almanac. New York: Oxford University Press, 1966, pp224-225. 